\title{
Preparation of a Novel Water-based Acrylic Multi-Thermal Insulation Coating
}

\author{
Xiufang YE, Dongchu CHEN*, Menglei CHANG, Youtian MO, Qingxiang WANG \\ School of Materials Science and Energy Engineering, Foshan University, Foshan 528000, Guangdong Province, China
}

cross ${ }^{\text {ref }}$ http://dx.doi.org/10.5755/j01.ms.23.2.16090

Received 19 August 2016; accepted 04 November 2016

\begin{abstract}
To efficiently improve the thermal insulation effect of coatings, a novel water-based acrylic multi-thermal insulation coating (multi-WATIC) combined with thermal obstruction, echo, and radiation was prepared. The category and ratio of thermal insulation functional fillers are crucial. First, water-based acrylic thermal insulation coating (WATIC) with single thermal insulation functional fillers was prepared, and the thermal insulation property tests were done. Thereafter, a novel multi-WATIC was prepared combined with the 3 thermal insulation functional fillers together, and the formula of the novel multi-WATIC was optimized based on single factor experiments by response surface methodology (RSM). Test results showed that multi-WATIC has excellent thermal insulation property, and the fitting result obtained by RSM is in good agreement with test data.

Keywords: waterborne, multi-thermal insulation, temperature difference, response surface methodology, optimization.
\end{abstract}

\section{INTRODUCTION}

Thermal insulation coatings control the temperature of buildings, improve indoor thermal comfort. They are a convenient and effective method to save energy [1-3]. Thermal insulation coatings can be divided into three different categories based on their mechanism: barrier, echo and radiation coatings. In America, Japan, Europe, and etc., thermal insulation coatings have already been studied and used widespread [4-7]. Researchers in China also have done much and made big improvements in this area up to now [8-12]. However, most research has focused on one or two thermal insulation mechanisms in tandem. As the thermal transfer of the object is always a combination of heat conduction, convection and radiation. Excellent thermal insulation coatings should incorporate more than one mechanism of thermal insulation. In fact, multi-thermal insulation coatings that combine thermal barrier, echo and radiation are a major goal, and high property multi-thermal insulation coatings should be investigated to satisfy the insufficiency of the energysaving material market.

Here, we prepared a novel water-based acrylic multithermal insulation coating (multi-WATIC). First, diatomite, hollow glass beads and powder of antimony tin oxide (ATO, nanometer) were used separately to obtain barrier, echo, and radiation thermal insulation coatings based on water-based acrylic emulsion. Thereafter, how these three thermal insulation functional fillers affect the thermal insulation property of WATIC was studied. Based on single factor experiments, a new technology compound with the three thermal insulation functional fillers was developed. Meanwhile, a novel water-based acrylic multithermal insulation coating (multi-WATIC) was prepared for the first time, and the formula of multi-WATIC was optimized by RSM. Test results show that the highest temperature difference of the novel multi-WATIC

\footnotetext{
* Corresponding author. Tel.: +86 75782988684 ; fax: +86 75782988684 . E-mail address: cdcever@163.com (D. Chen)
}

$\left(16.4{ }^{\circ} \mathrm{C}\right)$ is much higher than single thermal mechanical of WATIC (barrier is $3.9^{\circ} \mathrm{C}$, echo is $3.8^{\circ} \mathrm{C}$ and radiation is $12.5^{\circ} \mathrm{C}$ ). This result is similar to the value of $16.8^{\circ} \mathrm{C}$ predicated by response to a surface methodology model.

\section{EXPERIMENTAL DETAILS}

\subsection{Materials}

To prepare the WATIC, a waterborne acrylic emulsion was provided by Guangzhou RongDong chemical co., LTD., China. This was used as the matrix resin, the composition of the waterborne acrylic emulsion is a mixture of methyl methacrylate, 2-ethylhexyl acrylate, methyl acrylic acid, acrylamide and styrene. And the solid content of the emulsion is $47.5 \%$ (wt.\%), the $\mathrm{pH}$ value of the emulsion is 8.7 , the viscosity of the emulsion is $300 \mathrm{cps}$ and the acid value of the emulsion is $25 \mathrm{mg} \mathrm{KOH} / \mathrm{g}$.

To prepare the WATIC, thermal insulation functional fillers is the most important ingredients, in this study, diatomite, hollow glass beads and ATO nanometer powder were selected and purchased from Foshan AnYang Chemical Co., LTD., China. The main chemical composition of diatomite is $\mathrm{SiO}_{2}(\geq 86 \%$, wt.\%). Due to its special porous structure, diatomite can barrier thermal conduction effectively. The particle size of diatomaceous is $20-25 \mu \mathrm{m}$. Hollow glass beads is a kind of super lightweight inorganic materials powder. It has a hollow sphere structure, can reflect most of the energy from visible light, it usually used as echo thermal insulation functional filler. The particle size of diatomaceous is $30-80 \mu \mathrm{m}$. The main chemical composition of diatomite is $\mathrm{SiO}_{2}, \mathrm{Al}_{2} \mathrm{O}_{3}, \mathrm{ZrO}_{2}, \mathrm{MgO}$. ATO nanometer powder is a mixture of $\mathrm{SnO}_{2}$ and $\mathrm{Sb}_{2} \mathrm{O}_{3}$, present as dark blue, the mol ratio of $\mathrm{SnO}_{2}$ to $\mathrm{Sb}_{2} \mathrm{O}_{3}$ is $9: 1$. The particle size of ATO is $20-80 \mathrm{~nm}$. It can prevent the infrared and ultraviolet radiation effectively.

Mica powder and titanium dioxide were used as pigments and fillers. They were provided by Tianjing Fuchen Chemical Technology Co., Ltd., China. Mica 
powder is a kind of white powder with scaly structure, the diameter to thickness ratio higher than 70 . The main chemical composition of mica powder is $\mathrm{SiO}_{2}(49 \%$, wt. $\%)$ and $\mathrm{Al}_{2} \mathrm{O}_{3}(30 \%$, wt. $\%)$, and the particle size of mica powder is $5-10 \mu \mathrm{m}$. Titanium dioxide is the excellent fillers in coatings industry. The main chemical composition of titanium dioxide is $\mathrm{TiO}_{2}(93 \%$, wt. $\%)$, and the particle size of titanium dioxide is $30-50 \mu \mathrm{m}$.

Necessarily additives (such as dispersant, defoamer and film formers) were necessary to improve the coating quality, provided by Tianjing Damao Chemical Technology Co., Ltd., China.

\subsection{Coating preparation}

To obtain the WATIC, waterborne acrylic emulsion, thermal insulation functional fillers, solvents, and additives were prepared according to Table 1. The preparation process is shown in Fig. 1.

Table 1. Formula for thermal insulation coatings based on acrylic emulsion

\begin{tabular}{|l|c|c|}
\hline \multicolumn{2}{|c|}{ Materials } & Contents, wt.\% \\
\hline \multirow{2}{*}{ Resin } & $\begin{array}{c}\text { Waterborne Acrylic } \\
\text { Emulsion }\end{array}$ & $35-70$ \\
\hline $\begin{array}{l}\text { Thermal } \\
\text { insulation } \\
\text { functional fillers }\end{array}$ & Diatomite & \multirow{2}{*}{$0-25$} \\
\cline { 2 - 2 } & Hollow glass beads & \\
\cline { 2 - 3 } Additives & ATO & $0-5$ \\
\cline { 2 - 3 } & Dispersant(KH570) & $0-3$ \\
\cline { 2 - 3 } & Film former(PDMS) & $0-2$ \\
\hline \multirow{2}{*}{$\begin{array}{l}\text { Pigments and } \\
\text { fillers }\end{array}$} & Mica powder & $0-25$ \\
\hline Medium & Titanium dioxide & $0-30$ \\
\hline
\end{tabular}

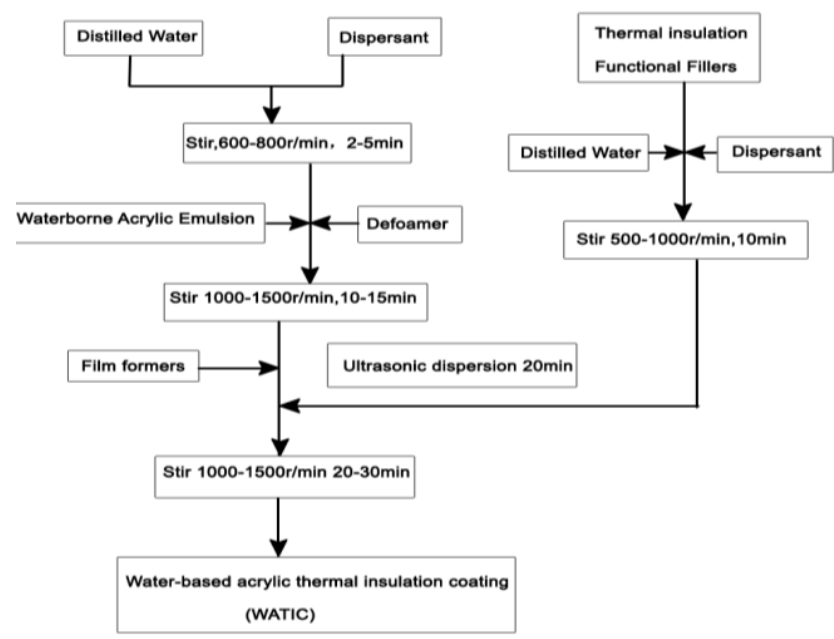

Fig. 1. Process flowchart of WATIC preparation

\subsection{Temperature difference analysis}

The test panel covered with WATIC was applied on a $70 \times 40 \times 2 \mathrm{~mm}$ aluminium panel (cleaned and dried). The thickness of dry coating was approximately $0.4 \mathrm{~mm}$. Meanwhile, ordinary water-based acrylic coating without thermal insulation functional fillers was also applied onto the same size aluminium panel and dried for blank test. The thermal insulation property of WATIC was evaluated by temperature difference through a self-developed lamp illumination apparatus according to the Chinese "building insulation coatings" standard (JG/T 235-2008) [9, 13-15]. The schematic of self-made device was shown in Fig. 2. The apparatus consists of one iodine tungsten lamp $(200 \mathrm{~W})$ fixed on the top of ceilings, an aluminium tested panel mentioned above and an expandable polystyrene (xPS) box with two separate chambers, each chamber contained two thermocouple probes. One thermocouple probe was used to measure the surface temperatures of the test panel $\left(T_{\mathrm{s}}\right)$, and the other one was used to measure the inside environment temperature of bottom chamber $\left(T_{\mathrm{i}}\right)$. When the panel was heated to a temperature balance, the relative temperature difference between the two thermocouple probes is recorded as $\Delta T\left(\Delta T=T_{\mathrm{s}}-T_{\mathrm{i}}\right)$. To ensure the accuracy of test, blank test was need at the same time, one panel painted with WATIC and the other panel painted with non-insulated ordinary water-based acrylic coating were tested at the same time. In order to eliminate the influence of other factor, obtain the exactly thermal insulation property of the functional fillers, sample and blank sample was tested in the same environment with the same test conditions. As mentioned above, after heating to temperature balance, the temperature on the sample surface is higher than temperature on bottom chamber, the temperature difference between the above two is recorded as $\Delta T$. To differentiate, $\Delta T_{\mathrm{t}}$ represents the temperature difference for WATIC and $\Delta T_{\mathrm{o}}$ for ordinary water-based acrylic coating (without any thermal insulation functional fillers) respectively. Therefore, the absolute temperature difference which represents the precise thermal insulation property of the test sample is recorded as $T_{\mathrm{d}}\left(T_{\mathrm{d}}=\Delta T_{\mathrm{t}}-\right.$ $\Delta T_{\mathrm{o}}$ ). In general, higher $T_{\mathrm{d}}$ represent better thermal insulation property.

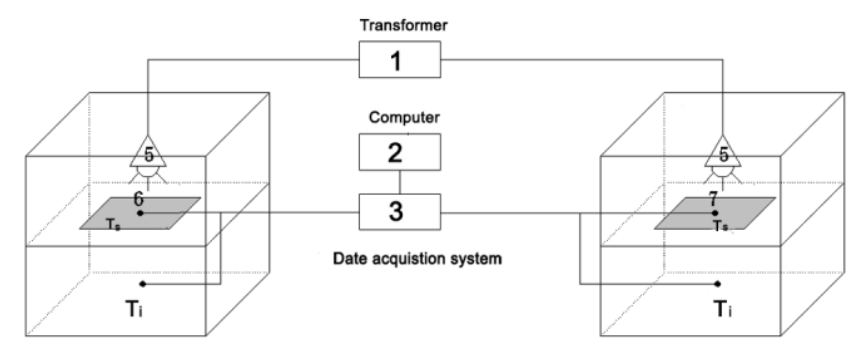

Fig. 2. Schematic illustration for the thermal insulation property measurements: 1-transformer; 2-data acquisition system; 3-computer; 4-xPS box; 5-iodine tungsten lamp $(200 \mathrm{~W}) ; 6$ - panel painted with WATIC; 7 -panel painted with non-insulated ordinary water-based acrylic coating

\section{RESULTS AND DISCUSSION}

\subsection{Single factor experiments of the three functional fillers}

For the principle of a central composite design under response surface methodology, the factors and levels that effect the model should be confirmed based on single factor experiments first, then a series of experiments and analysis should be done according to a central composite 
design to obtain the optimal value of all the selected factors. Based on these, how the three thermal insulation functional fillers affect the thermal insulation property of WATIC was studied first in this study, using the principle of a central composite design under response surface methodology [16-17], the content and the category of the three different functional fillers were considered as significant factors to temperature difference of WATIC. So single factor experiment was studied in detail, barrier, echo and radiation thermal insulation coatings were prepared with certain thermal insulation functional fillers respectively. For barrier water-based acrylic thermal insulation coating means in this coating, the thermal insulation functional filler is just diatomite, echo waterbased acrylic thermal insulation coating means in this coating, the thermal insulation functional filler is just hollow glass beads, radiation water-based acrylic thermal insulation coating means in this coating, the thermal insulation functional filler is just ATO nanometer powder. The temperature difference analysis was done to evaluate thermal insulation property of these 3 functional fillers. Variation rules of absolute temperature differences are shown in Fig. 3.

Fig. $3 \mathrm{a}-\mathrm{c}$ shows the rules of absolute temperature differences of WATIC with different weight contents of thermal insulation functional fillers. It clearly indicates that the $T_{\mathrm{d}}$ of WATIC contained any category of the 3 functional filler is higher than ordinary water-based acrylic coating without functional fillers. That means either functional filler (diatomite, hollow glass beads and ATO) has exceptional thermal insulation property.

Fig. 3 and Fig. 4 clearly show that for all the 3 functional fillers, curve of temperature difference $\left(T_{\mathrm{d}}\right)$ change with the weight content of the functional fillers, but the rules between the $T_{\mathrm{d}}$ and the weight content of either functional fillers are non-linear. For barrier thermal insulating coating, the $T_{\mathrm{d}}$ dropped after initially increasing. The highest $T_{\mathrm{d}}$ can be up to $3.9^{\circ} \mathrm{C}$ when the weight content of diatomite is $3 \mathrm{~g}$.

Hollow glass beads have low thermal conductivity due to its hollow structure, is used to prepare the echo thermal insulating coatings $[9,18,19]$. Test results show that the $T_{\mathrm{d}}$ of WATIC with hollow glass beads can be up to $3.8^{\circ} \mathrm{C}$ when its weight content is $7 \mathrm{~g}$.

When the weight content of ATO is $2.5 \mathrm{~g}$, the $T_{\mathrm{d}}$ of the radiation WATIC can be up to $12.5^{\circ} \mathrm{C}$, much higher than the other two functional fillers. This probably due to ATO can absorb both visible and near infrared radiation, when used as thermal insulation functional fillers, it shows excellent thermal insulation performance [10, 20].

As mentioned above, temperature difference analysis results showed that the thermal insulation property of WATIC not only affected by the weight content of functional fillers, the category of functional fillers can also affect the thermal insulation property of WATIC at the same time. Test data indicate that, for all the 3 functional fillers, the temperature difference does not always increase while more functional fillers were added into coating system. There is a maximum $T_{\mathrm{d}}$ in the experiment range for each single functional filler as shown in Fig. 4.

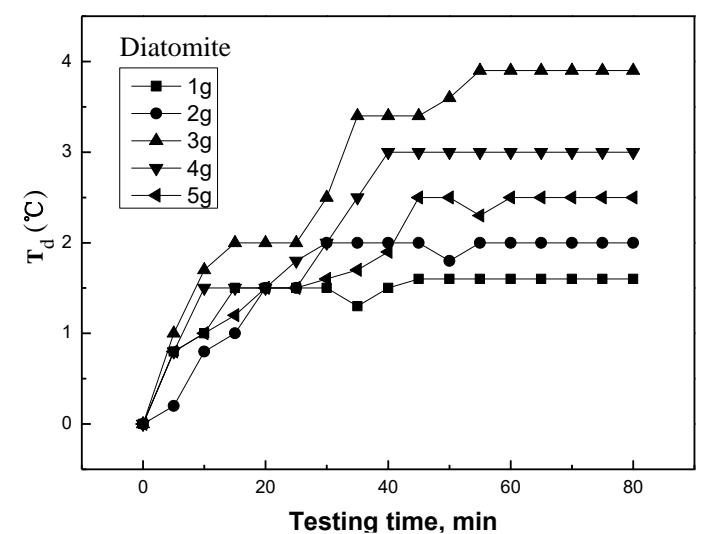

a-barrier water-based acrylic thermal insulation coating

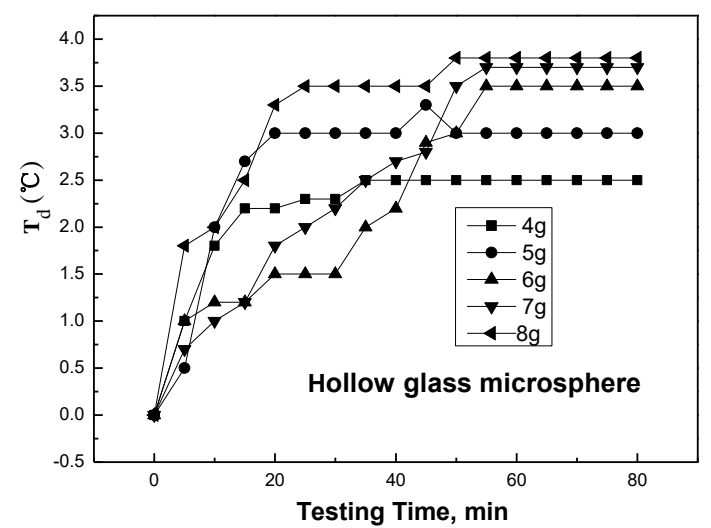

b-echo water-based acrylic thermal insulation coating

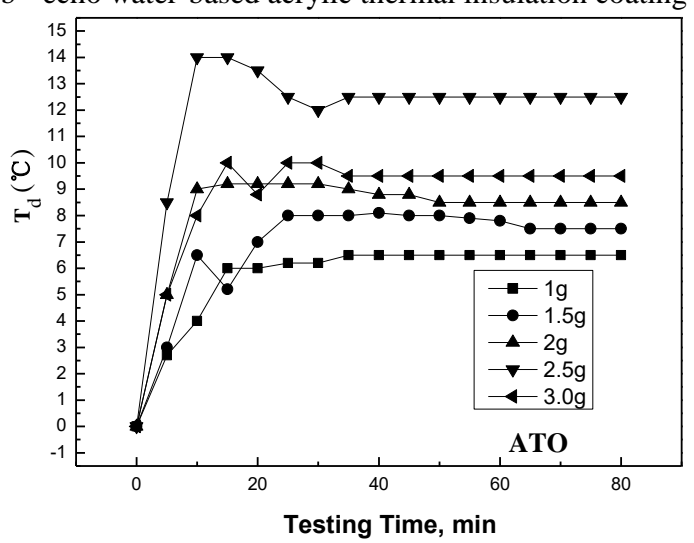

c-radiation water-based acrylic thermal insulation coating

Fig. 3. The absolute temperature differences of WATIC based on single insulation mechanism

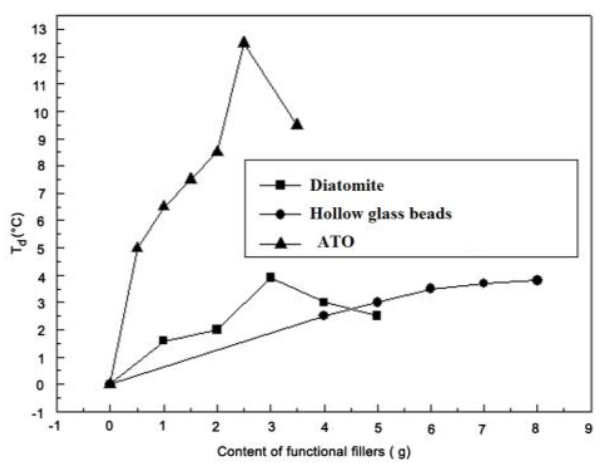

Fig. 4. Variation rules of $T_{\mathrm{d}}$ on the basis of category and weight content of thermal insulation functional fillers 


\subsection{Formula optimized by response surface methodology}

According to the results of single factor experiments, the category and weight content of functional fillers were considered significant to the thermal insulation property of WATIC

In order to obtain the optimal formula of multiWATIC, all the 3 single factors were optimized by RSM through a full-factorial central composite design. Thereafter, a three-factor, three-level experiment design was adopted as shown in Table 2 and Table 3 taking the weight content and the category of functional fillers as the variations.

Table 2. Factors and levels in RSM design

\begin{tabular}{|l|c|c|c|c|}
\hline \multirow{2}{*}{ Variables } & \multicolumn{3}{|c|}{ Values } & \multirow{2}{*}{ Code value } \\
\cline { 2 - 5 } & -1 & 0 & +1 & \\
\hline Diatomite, g & 1 & 2 & 3 & $A$ \\
\hline Hollow glass beads, g & 4 & 5 & 6 & $B$ \\
\hline ATO powder, g & 1.5 & 2.5 & 3.5 & $C$ \\
\hline
\end{tabular}

According to the rule of full-factorial central composite design, three-factor experimental variables-diatomite, hollow glass beads and ATO-in three-level required 17 experiments. For all these 17 experiments, the optimization of variables, sum of squares, degree of freedom, mean square, $F$-value, values of $" P>F^{\prime \prime}$ and etc. were all determined by Design-Expert Software 8.0. The actual values of temperature difference for the variables are given in Table 4.

Correlating the thermal insulation property of WATIC with functional fillers is a basis for optimization the formula of multi-WATIC.

The variance on the absolute temperature difference of multi-WATIC, which was analysed by the Design Expert 8.0 software, is shown in Table 4. Based on these, a polynomial equation was set up as following:

$$
\begin{aligned}
& Y=9.00-0.19 A+0.13 B-0.063 C+0.62 A B+0.50 A C- \\
& 0.13 B C-0.75 A^{2}-0.38 B^{2}-1.25 C^{2} .
\end{aligned}
$$

In the equation above, $Y$ is the predicted response $\left(T_{\mathrm{d}}\right)$, meanwhile, $A, B, C$ are represented the weight content of diatomite, hollow glass beads and ATO, respectively.
Table 3. The design of RSM experiments and the corresponding $T_{\mathrm{d}}$ of the WATIC samples

\begin{tabular}{|c|c|c|c|c|}
\hline \multirow{2}{*}{ RUN } & \multicolumn{3}{|c|}{ Variables/Levels } & \multirow{2}{*}{ Response, $T_{\mathrm{d}}{ }^{\circ} \mathrm{C}$} \\
\cline { 2 - 4 } & $A$ & $B$ & $C$ & 13.5 \\
\hline 1 & 1 & 1 & 0 & 12.5 \\
\hline 2 & -1 & 0 & -1 & 12.0 \\
\hline 3 & 0 & 1 & -1 & 16.5 \\
\hline 4 & 0 & 0 & 0 & 12.5 \\
\hline 5 & 1 & 0 & 1 & 14.0 \\
\hline 6 & 1 & 0 & -1 & 15.5 \\
\hline 7 & -1 & 1 & 0 & 14.5 \\
\hline 8 & -1 & -1 & 0 & 15.3 \\
\hline 9 & -1 & 0 & 1 & 13.0 \\
\hline 10 & 0 & -1 & -1 & 16.5 \\
\hline 11 & 0 & 0 & 0 & 16.4 \\
\hline 12 & 0 & 0 & 0 & 16.6 \\
\hline 13 & 0 & 0 & 0 & 13.0 \\
\hline 14 & 0 & 1 & 1 & 15.5 \\
\hline 15 & 0 & -1 & 1 & 16.8 \\
\hline 16 & 0 & 0 & 0 & 12.5 \\
\hline 17 & 1 & -1 & 0 & \\
\hline
\end{tabular}

Usually, " $P>F^{\prime}$ value was used to validate the regression coefficient in RSM, if " $P>F^{\prime \prime}$ value lower than 0.05 means model terms are excellent. In this case, as seen in Table 4, $A-A, B-B, A B, A^{2}, B^{2}, C^{2}$ are crucial model terms. They had a significant effect on the temperature difference of multi-WATIC. It is noteworthy that $F$-values farther from unity, this verified that the factors can explained the variations properly. That is, the estimated factor effects are real. Fig. 5 shows the interaction of the $\mathrm{AB}$ (diatomite and hollow glass beads), AC (diatomite and ATO) and BC (hollow glass beads and ATO) on the temperature difference of multi-WATIC.

According to the polynomial equation, drawing the response surface plot showing the interactive effects of either two variables on the temperature difference of multiWATIC while the third variable at it is fixed level.

Based on the single factor experiments of the three functional fillers ( 3 variables), the constant value of the third variable setted at fixed level " 0 ". The plots are shown in Fig. 5.

Fig. 5 a shows that when the weight content of ATO is constant, the interaction effects between the diatomite and the hollow glass beads on the thermal insulation property is significant.

Table 4. The analysis results of variance by central composite quadratic model

\begin{tabular}{|c|c|c|c|c|c|}
\hline Source & Degree of freedom & Sum of squares & Mean square & $F$ value & $P>F$ \\
\hline Model & 9 & 41.78 & 4.64 & 5.62 & 0.00165 \\
\hline A-A & 1 & 2.53 & 2.53 & 3.07 & 0.1234 \\
\hline B-B & 1 & 3.13 & 3.13 & 3.78 & 0.0928 \\
\hline C-C & 1 & 0.28 & 0.28 & 0.34 & 0.5778 \\
\hline AB & 1 & 4.00 & 4.00 & 4.84 & 0.0636 \\
\hline AC & 1 & 0.56 & 0.56 & 0.68 & 0.4364 \\
\hline BC & 1 & 0.00 & 0.00 & 0.00 & 1.0000 \\
\hline A $^{2}$ & 1 & 14.29 & 14.29 & 17.31 & 0.0042 \\
\hline B $^{2}$ & 1 & 6.24 & 6.24 & 7.56 & 0.0285 \\
\hline C $^{2}$ & 1 & 7.59 & 7.59 & 9.19 & 0.0191 \\
\hline Lesidual & 7 & 5.78 & 0.83 & & \\
\hline Pure Error & 3 & 5.69 & 1.90 & & \\
\hline Corrected Total & 16 & 47.56 & & & \\
\hline
\end{tabular}



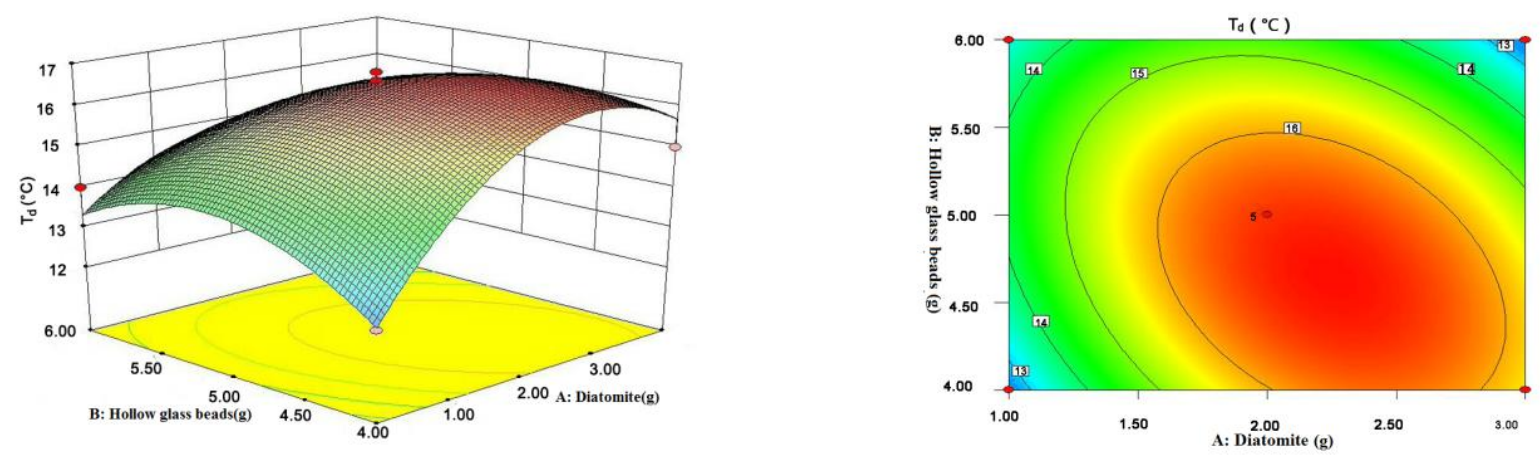

$\mathrm{a}$-the interaction of the $\mathrm{AB}$ on the temperature difference of multi-WATIC
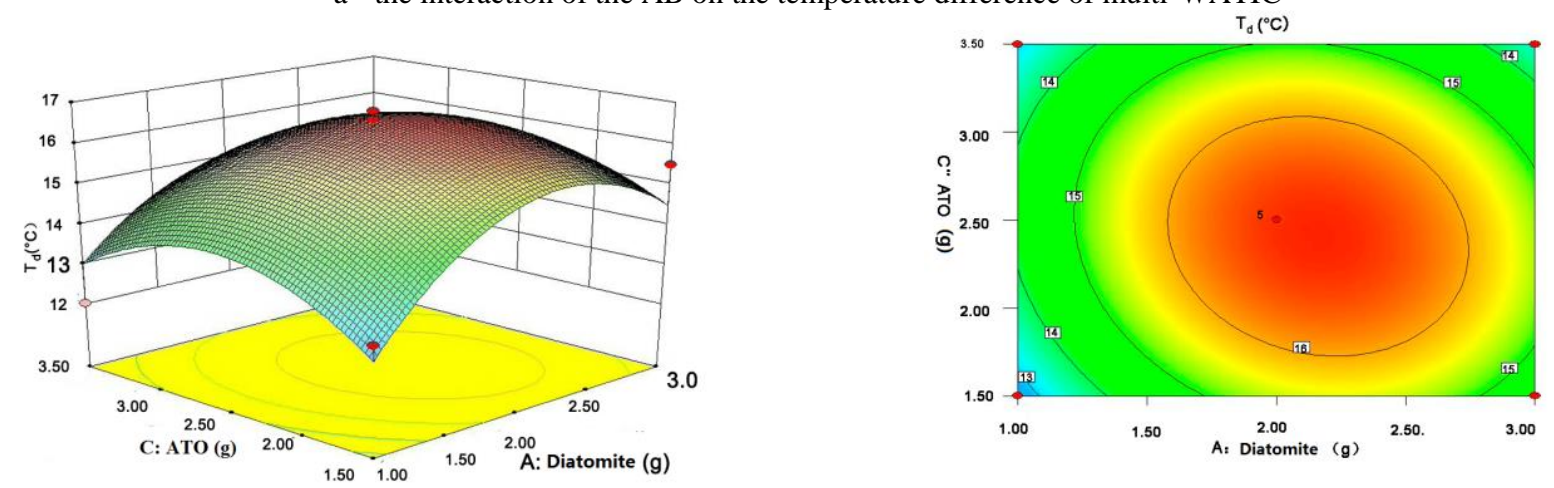

$\mathrm{b}$-the interaction of the AC on the temperature difference of multi-WATIC
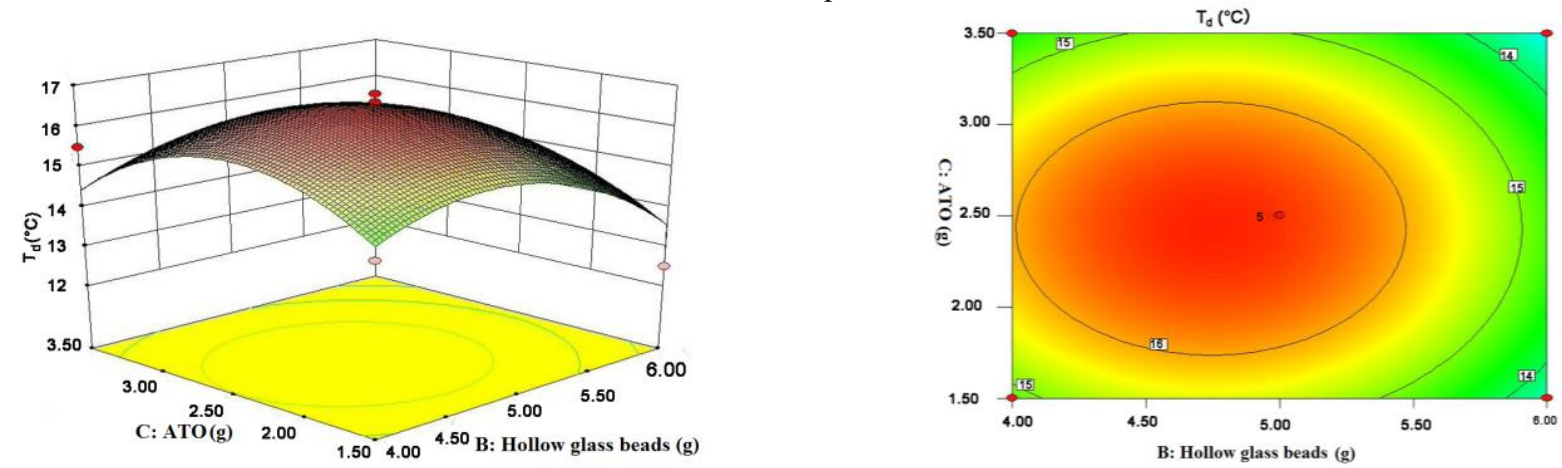

$\mathrm{c}$ - the interaction of the $\mathrm{BC}$ on the temperature difference of multi-WATIC

Fig. 5. Analysis of variance based on full-factorial central composite quadratic model

The response value-- absolute temperature difference $\left(T_{\mathrm{d}}\right)$ rise with the content of diatomite and the hollow glass beads increases. When the content of diatomite and the hollow glass beads rise to a certain degree, the response value $T_{\mathrm{d}}$ reached the maximum value. Keep on increase the content of diatomite and the hollow glass beads, the value of $T_{\mathrm{d}}$ decrease. The results indicate that while the content of diatomite and the hollow glass beads is too low or too high would both depress the response value of $T_{\mathrm{d}}$, only when they get to a moderate value, the thermal insulation property of multi-WATIC $\left(T_{\mathrm{d}}\right)$ can reached to a maximum value.

Fig. $5 \mathrm{~b}$ is the response surface plot showing the interactive effects of the content of diatomite and ATO on $T_{d}$ of multi-WATIC when the weight content of hollow glass beads is constant. The response value $-T_{\mathrm{d}}$ rise with the content of diatomite and ATO increases until reached at the maximum value when the content of diatomite and ATO rise to a certain degree. Keep on increase the content of diatomite and ATO, the response value of $T_{\mathrm{d}}$ decrease.
The plot indicates that while the content of diatomite and ATO is too low or too high would both depress the value of $T_{\mathrm{d}}$, only when they get to a moderate value, the thermal insulation property of multi-WATIC $\left(T_{\mathrm{d}}\right)$ can reached to a maximum value.

Fig. $5 \mathrm{c}$ shows that when the weight content of diatomite is constant, the interaction effects between the ATO and the hollow glass beads on the thermal insulation property. The response value $-T_{\mathrm{d}}$ rise with the content of ATO and the hollow glass beads increases. When the content of ATO and the hollow glass beads rise to a certain degree, the response value $T_{\mathrm{d}}$ reached the maximum value. Keep on increase the content of ATO and the hollow glass beads, the value of $T_{\mathrm{d}}$ decrease. The results indicate that while the content of ATO and the hollow glass beads is too low or too high would both depress the value of $T_{\mathrm{d}}$, only when they get to a moderate value, the thermal insulation property of multi-WATIC $\left(T_{\mathrm{d}}\right)$ can reached to a maximum value. Meanwhile, the iso-response 3D surface graphic Fig. 5 (a) is steeper than Fig.5 (b) and Fig. 5 (c). This 
suggests that the interaction between diatomite and the hollow glass beads has the greatest influence on the thermal insulation property of the multi-WATIC.

Through moving both the major and minor axis along of the contour line to determin the statistical optimal values ( $\left.T_{\mathrm{d}}\right)$, the maximum $T_{\mathrm{d}}$ can be obtained when the response arrived at the center point. Thereafter, from the 3D plots shown in Fig. 5, the optimal concentration values for $A, B$, and $C$ (diatomite, hollow glass beads and ATO) were identified as $2.3,4.6$ and $2.4 \mathrm{~g}$, respectively. Thus, the formula of the multi-WATIC optimized by response surface methodology is as seen in Table 5. The maximum $T_{\mathrm{d}}$ can be up to $16.8{ }^{\circ} \mathrm{C}$ as predicated by the model. This is much higher than the $T_{\mathrm{d}}$ of multi-WATIC with just one single mechanism functional fillers $(A, B$, or $C)$ as seen in Fig. 3 and Fig. 4.

Table 5. The formula of the composite multi-WATIC

\begin{tabular}{|l|c|c|}
\hline \multicolumn{2}{|c|}{ Materials } & Contents, wt.\% \\
\hline \multirow{2}{*}{ Resin } & $\begin{array}{c}\text { Waterborne acrylic } \\
\text { emulsion }\end{array}$ & $35-70$ \\
\hline \multirow{2}{*}{$\begin{array}{l}\text { Thermal insulation } \\
\text { functional fillers }\end{array}$} & Diatomite & $2-5$ \\
\cline { 2 - 3 } & Hollow glass beads & $5-8$ \\
\cline { 2 - 3 } & ATO & $0.5-3$ \\
\hline \multirow{3}{*}{ Additives } & Dispersant(KH570) & $1-5$ \\
\cline { 2 - 3 } & Defoamer(PDMS) & $0.5-3$ \\
\cline { 2 - 3 } & Film formers(CS-12) & $0.5-2$ \\
\hline \multirow{2}{*}{ Pigments and fillers } & Mica powder & $0-25$ \\
\cline { 2 - 3 } & Titanium dioxide & $0-30$ \\
\hline Medium & Distilled water & $20-45$ \\
\hline
\end{tabular}

\subsection{Confirmatory test of the model}

This study shows that the formula of a novel multiWATIC system was optimized by response surface methodology. For the novel multi-WATIC, three different categories of functional fillers were contained. As a result, it can promote the collaborative thermal insulation effects including obstruction, radiation, and echo. The absolute temperature difference $T_{\mathrm{d}}$ could be up to $16.8^{\circ} \mathrm{C}$ as predicated. Thus, to verify this prediction, a multi-WATIC is prepared according to the formula seen in Table 5. The $T_{\mathrm{d}}$ of the novel multi-WATIC was tested with the thermal insulation property measurements mentioned in Fig. 2. The result showed that the $T_{\mathrm{d}}$ of the multi-WATIC is $16.4{ }^{\circ} \mathrm{C}$, which agrees well with the predicted result.

\section{CONCLUSIONS}

1. The three thermal insulation functional fillers: diatomite, hollow glass beads, and ATO nanometer powder, has significant effect the thermal insulation property of WATIC.

2. In the formula for a novel multi-WATIC optimized by the response surface methodology, the content of diatomite, hollow glass beads and ATO nanometer powder are $2.3 \mathrm{~g}, 4.6 \mathrm{~g}$, and $2.4 \mathrm{~g}$, respectively.

3. Temperature difference analysis showed that the $T_{\mathrm{d}}$ of the optimized multi-WATIC is $16.4{ }^{\circ} \mathrm{C}$. This is much higher than the $T_{\mathrm{d}}$ of the WATIC with just one single mechanism functional filler. This means that the
multi-WATIC has excellent thermal insulation property as expected.

4. For the absolute temperature difference of the optimized multi-WATIC, the predicted value of $16.8^{\circ} \mathrm{C}$ agrees very well with the experimental value of $16.4{ }^{\circ} \mathrm{C}$. That is, the response surface methodology is very effective in formula optimization.

\section{Acknowledgments}

This work was financially supported by Foundation for Distinguished Young Talents in Higher Education of Guangdong, China (2015KQNCX178). And project supported by the Doctoral Fund of Foshan University, China (2014GQ100131).

\section{REFERENCES}

1. Santamouris, M., Pavlou, K., Synnefa, A., Niachou, K., Kolokotsa, D. Recent Progress on Passive Cooling Techniques Advanced Technological Developments to Improve Survivability Levels In Low-Income Households Energy and Buildings 39 2007: pp. 859-866.

2. Synnefa, A., Santamouris, M., Apostolakis, K. On the Development, Optical Properties and Thermal Property of Cool Colored Coatings For The Urban Environment Solar Energy 81 2007: pp. 488-497.

3. Mohammad, S. Performance Characteristics and Practical Applications of Common Building Thermal Insulation Materials Building and Environment 40 2005: pp. 353-366.

4. Karlessi, T., $\quad$ Santamouris, M., $\quad$ Synnefa, A., Assimakopoulos, D., Didaskalopoulos, P., Apostolakis, K. Development and Testing of PCM Doped Cool Colored Coatings to Mitigate Urban Heat Island and Cool Buildings Building and Environment 46 2011: pp. 570-576.

5. Hui, S., Hongwei, T., Athanasios, T. The Effect of Echo Coatings on Building Surface Temperatures, Indoor Environment and Energy Consumption-An Experimental Study Energy and Buildings 43 2011: pp. 573-580.

6. Wang, X., Kendrick, C., Ogden, R., Maxted, J. Dynamic Thermal Simulation of a Retail Shed With Solar Reflective Coatings Applied Thermal Engineering 28 2008: pp. 1066-1073.

7. Levinson, R., Akbaria, H., Reilly, J.C. Cooler Tile-Roofed Buildings With Near Infrared-Reflective Non-White Coatings Building and Environment 42 2007: pp. $2591-2605$. https://doi.org/10.1016/j.buildenv.2006.06.005

8. Jianrong, S., Jie, Q., Jian, Q., Zhongnan, S., Weidong, Z., Xiao, X., Yunxing, S., Tao, Z., Wenzhan, J., Rongpu, Z., Hongqiang, Z., Ziying, Z., Xiong, W. The Effects of Particle Size Distribution on the Optical Properties of Titanium Dioxide Rutile Pigments and Their Applications in Cool Non-White Coatings Solar Energy Materials and Solar Cells 130 2014: pp. 42-50. https://doi.org/10.1016/j.solmat.2014.06.035

9. Guo, W., Qiao, X., Huang, Y., Fan, M., Han, X. Study on Energy Saving Effect of Heat-Reflective Insulation Coating on Envelopes in the Hot Summer and Cold Winter zone Energy and Buildings 50 2012: pp. 196-203.

10. Jian, Q., Jianrong, S., Jie, Q., Zhongnan, S., Weidong, Z., Yunxing, S., Tao, Z., Hongqiang, Z., Rongpu, Z., Zhongyu, H., Xiao, X. Transparent Thermal Insulation 
Coatings For Energy Efficient Glass Windows and Curtain Walls Energy and Buildings 77 2014: pp. 1-10.

11. Lu, K., Ji, Z., Kong, Z., Li, H., Zhang, J. Preparation and Thermal Insulating Properties of Antimony Doped NanoSno2/Waterborne Polyurethane Composite Coatings Journal of Inorganic Materials 27 2012: pp. 1117-1120. https://doi.org/10.3724/SP.J.1077.2012.12231

12. Dai, Z., Li, Z., Li, L., Xu, G. Synthesis and Thermal Properties of Antimony Doped Tin Oxide/Waterborne Polyurethane Nanocomposite Films as Heat Insulating Materials Polymers for Advanced Technologies 22 2011: pp. $1905-1911$.

13. Song, Z., Zhang, W., Shi, Y., Song, J., Qu, J., Zhang, T., Li, Y., Zhang, H., Zhang, R. Optical Properties Across the Solar Spectrum and Indoor Thermal Performance of Cool White Coatings For Building Energy Efficiency Energy and Buildings 63 2013: pp. 49-58.

14. Shi, Y., Song, Z., Zhang, W., Song, J., Qu, J., Wang, Z., Li, Y., Xu, L., Lin, J. Physicochemical Properties of DirtResistant Cool White Coatings for Building Energy Efficiency Solar Energy Materials and Solar Cells 110 2013: pp. $133-139$.

15. Ye, X., Chen, D., Chang, M., Liang, Q., Lu, Q. The Preparation of Fluorocarbon Thermal Insulation Coating with Different Fillers Advanced Materials Research

1101 2015: pp. 36-39.

16. Zhou, G., Fu. L., Li, X. Optimization of UltrasoundAssisted Extraction Conditions for Maximal Recovery of Active Monacolins and Removal of Toxic Citrinin from Red Yeast Rice By a Full Factorial Design Coupled with Response Surface Methodology Food Chemistry 170 2015: pp. 186-192.

17. Mangili, I., Oliveri, M., Anzano, M., Collina, E., Pitea, D., Lasagni, M. Full Factorial Experimental Design to Study the Devulcanization of Ground Tire Rubber in Supercritical Carbon Dioxide Journal of Supercritical Fluids 92 2014: pp. 249-256.

18. Synnefa, A., Santamouris, M., Livada, I. A study of the Thermal Performance of Reflective Coatings for the Urban Environment Solar Energy 80 2006: pp. 968-981.

19. Liu, J., Li, X., Wei, G. Properties of Waterborne SolarReflective Heat-Insulating Coatings Journal of Beijing University of Chemical Technology (Natural Science Edition) 36 2009: pp. 44-49.

20. Wang, X., Hu, Y., Song, L., Xing, W., Lu, H., Lv, P., Jie, G. Effect of Antimony Doped Tin Oxide on Behaviors of Waterborne Polyurethane Acrylate Nanocomposite Coatings Surface \& Coatings Technology 205 2010: pp. $1864-869$. 